\title{
Passing a baton to the next generation
}

\author{
Toshio Suda $\cdot$ Toshio Kitamura
}

Published online: 8 November 2012

(c) The Japanese Society of Hematology 2012

\section{Past Editor-in-Chief, Toshio Suda, MD}

The International Journal of Hematology (IJH) has a long history in Japan, dating back to 1937. In 1991, the IJH passed a milestone in its history with the transition to a truly international journal under the helm of Dr. Yataro Yoshida as Editor-in-Chief. To mark that occasion, the name of the journal was changed from "Acta Haematologica Japonica" to "International Journal of Hematology." This was a reform that revitalized the journal. During his term, Dr. Yoshida also initiated the "Progress in Hematology", a series of review articles focusing on the latest information and insights into important areas of the field. The Japanese Society of Hematology and the Japanese Society of Clinical Hematology merged in 2008 and, along with Risho Ketsu-eki (a journal in Japanese), the IJH now serves as the official journal for this newly united society. Since 2008, IJH started an electric submission and review system which works very well. The number of submissions has increased to more than 800 per year, of which domestic submissions only account for $30 \%$ of the total and publication became monthly from 2011. The current acceptance rate is approximately $30 \%$, and the average review period is $<3$ weeks.

When I was appointed Editor-in-Chief in 2005, I was confident I would be able to raise the journal's impact factor (IF). However, this may have been over-optimistic,

T. Suda $(\bowtie)$

School of Medicine, Keio University, Tokyo, Japan

e-mail: suda.editor.ijh@gmail.com

\section{T. Kitamura}

Division of Cellular Therapy, The Institute of Medical Science,

The University of Tokyo, Tokyo, Japan given the tremendous competition in publishing in the field of hematology. I believe that the merits of an article cannot be measured solely by the impact factor of the journal in which it is published. However, we cannot ignore the influence of a high IF in attracting the submission of interesting articles. Although this is my personal opinion, Japanese scientists tend to easily respect foreign articles and to view those published by Japanese authors more stringently. This may reflect the lingering influence of the notion of wakon-yousai, a concept from the time of the 19th century Meiji restoration, which called for the embrace of "acceptance technology", while preserving the "Japanese spirit". Thus, Japanese researchers are not only reluctant to submit but also cite to IJH papers. We should be more confident in our achievements. I think it is very important to have in mind that "IJH is my journal". We should make every effort to share information on scientific and clinical developments from Japan and across Asia.

As I end my term as Editor-in-Chief, I would like to acknowledge all the members who have been involved in the IJH publication: authors, reviewers and members of editorial board and associate editors. I believe that members on the editorial board and publication office work very hard every day. I would like to pass the baton to Dr. Toshio Kitamura at the Institute of Medical Science, University of Tokyo.

\section{Editor-in-Chief, Toshio Kitamura, MD}

From this issue, I will serve as Editor-in-Chief for the International Journal of Hematology, taking the baton from the former Editor-in-Chief Dr. Toshio Suda. I am deeply honored to be named Editor-in-Chief of this longlived hematology journal. I believe that the quality of the 
journal has greatly improved thanks to the continuing efforts of Dr. Suda and everyone involved in publishing the IJH, and so I will attempt to maintain this trend to further strengthen the journal. Although the impact factor has remained somewhat low. This may be explained by several factors, including one suggested by Dr. Suda. Although the quality of the journal is not fully represented by the impact factor, a high impact factor is nonetheless important for attracting high-quality submissions. I will therefore make every effort to increase the impact factor of this journal while maintaining the quality of the content, which I feel merits wider international recognition. Clearly, the most important thing is to publish many article with real impact in the field of hematology. I hope that IJH will become a leading journal in hematology, and continuously contribute to the field. 